\title{
Incidencia de muerte por ahorcamiento, 2010 a 2012
}

\author{
Rosario Lira, Karina Pariona, Rosángela Vargas, Rosa Carrera, Shérmany Aronés
} Instituto de Medicina Legal, Ministerio Público, e Instituto de Patología, UNMSM

Introducción: Asfixia mecánica por ahorcadura es el mecanismo suicida reportado más frecuente, por constricción del cuello ejercido por lazo sujeto a punto fijo, sobre el cual ejerce traición el peso del cuerpo.

Objetivos: Determinar la incidencia por edad, sexo, tipo de ahorcaduras, lesiones cervicales, caracteres del surco cutáneo y etiología médico legal.

Diseño: Cuantitativo, descriptivo, transversal.

Institución: Instituto de Medicina Legal, Ministerio Público, e Instituto de Patología, UNMSM.

Material de estudio: Informes periciales de necropsias ingresadas a Morgue Central de Lima.

Intervenciones: Médico legales, por denuncia al Ministerio Público por muerte violenta.

Principales medidas de resultados: Medidas de tendencia central porcentual.

Resultados: Se seleccionó 228 protocolos de necropsias del total de necropsias, de julio 2010 a junio 2012. Sexo masculino 70,2\% (168), femenino 26,3\% (60); grupo etario 20 a 29, 30,7\% (70), de 11 a 19, 20,2\% (46); suspensión completa 17,5\% (40), incompleta 82,5\% (188); surco cutáneo ascendente, incompleto suprahioideo 95\% (218); etiología suicida $97,4 \%$ (222), homicida 2,2\% (5), accidental 0,4\% (01); alcoholemia 10\% (23); patología coexistente 5\% (12), neoplasia maligna 8, tiroiditis crónica 2, VIH 2; mujeres en edad fértil de 15 a 49, 66\% (40); signos de gestación interrumpida 15\% (06); esperma anogenital 03.

Conclusiones: Existencia de tendencia suicida en personas jóvenes de sexo masculino, con suspensión incompleta, suprahioideo.

Palabras clave: Ahorcamiento, asfixia mecánica, asfixia por constricción.

\section{Incidencia de muerte y caracteres de heridas de ingreso por proyectil de armas de fuego. Morgue de Lima, enero-abril 2012}

\author{
Mario Castro, Rosa Carrera, Shérmany Aronés, Rosario Lira, Sonia Fernández, Daniel Cavero \\ Instituto de Medicina Legal, Ministerio Público, e Instituto de Patología, UNMSM
}

Introducción: Las heridas por proyectil de arma de fuego (PAF), dejan características que permiten estimar distancia del disparo, siendo primordial identificarlas para adecuado diagnóstico de proximidad del disparo.

Objetivos: Establecer incidencia y caracteres en heridas de ingreso, en cadáveres por PAF.

Diseño: Descriptivo, retrospectivo, transversal.

Institución: Instituto de Medicina Legal, Ministerio Público, e Instituto de Patología, UNMSM.

Material de estudio: Informes periciales de necropsias medicolegales.

Intervenciones: Revisión de protocolos de necropsia y exámenes auxiliares.

Principales medidas de resultados: Medida de tendencia central porcentual.

Resultados: Se seleccionó 72 (4,5\%) casos de muerte por PAF, de 1594 cadáveres ingresados a morgue de Lima entre enero y abril 2012, masculino 94,4\% (68), femenino 5,6\% (04); grupo etario predominante 20 a 29 años 27,8\% (20), seguido de 40 a 49 con 23,6\% (17); etiología predominante homicida $84,7 \%$ (61), suicida 13,9\% (10), accidental 1,4\% (01); compromiso corporal de un segmento 63,9\% (46), cabeza 52,8\% (38); dos segmentos 26,4\% (19), tres segmentos 6,9\%( 05); heridas perforantes 45,8\% (33), penetrantes 36,1\% (26), ambas 18,1\% (13); sin signos de proximidad $69,4 \%$ (50), con signos de proximidad 29,2\% (21); proyectil único $72,2 \%$ (52), seguido de tres proyectiles 12,5\% (09); alcoholemia 26,4\% (19), negativa 73,6\% (53); ninguno drogas de abuso; sin atención médica 55,6\% (40), con atención $44,4 \%$ (32).

Conclusiones: El 71\% (51) correspondió a grupo etario 20 a 49 años, etiología homicida, segmento mayor comprometido fue la cabeza con un proyectil, sin signos de proximidad.

Palabras clave: Proyectiles, armas de fuego, patología forense, homicidio. 